\title{
Studies on Haemostatic Parameters of Type 2 Diabetics in Owerri, Imo State
}

\author{
Edward Ukamaka $C^{1^{*}}$, Nwanjo Harrison $\mathrm{U}^{1}$, Nwosu Dennis $\mathrm{C}^{1}$, and Obeagu Emmanuel Ifeanyi ${ }^{1,2}$ \\ ${ }^{1}$ Department of Medical Laboratory Science, Imo State University, Owerri, Nigeria \\ ${ }^{2}$ Medical Laboratory Science, University Health Services, Michael Okpara University, Umudike, Abia State, Nigeria
}

DOI: $10.36348 /$ SJMPS.2019.v05i10.004

| Received: 02.10.2019 | Accepted: 09.10.2019 | Published: 11.10.2019

*Corresponding author: Edward Ukamaka C

\section{Abstract}

Type 2 diabetes mellitus is a chronic metabolic disorder which has emerged as a health challenge globally due to its insidious on set, late recognition and complications. The present study was aimed at evaluation of haemostatic parameters in Owerri. Cross Sectional Studies was conducted at Federal Medical Center and Imo State specialist Hospital, Owerri. A total of three hundred subjects which include each one hundred and fifty type 2 diabetics and apparently control subjects between the ages forty and sixty nine years were recruited. Ten millimeters of venous blood as aseptically collected from thesubjects. Platelet count and coagulation assay were used for determination of these parameters . The data was analyzed using statistical package for social science 20.0. Test with a probability value of $\mathrm{P}<0.05$ was considered statistically significant. Results from haemostatic parameters showed higher statistically significant value $(\mathrm{P}=0.001)$ in platelet count $\left(226.68 \pm 19.40\right.$ vs $\left.205.86 \pm 13.33 \times 10^{9} / \mathrm{l}\right)$, and fibrinogen $(370.19) \pm 21.55$ v $2.63 .56 \pm 32.31 \mathrm{mg} / \mathrm{dl}$ ) when type 2 diabetics was compared with control subjects. Inversely, there was statistically significantly lower values; $(\mathrm{P}=0.031)$ in prothrombin time $(13.47 \pm 0.96 \mathrm{v} 14.06 \pm 0.96 \mathrm{~s})$ and $(\mathrm{P}=0.001)$ in activated partial thrombopalstin time $(34,39 \pm 2.17$ v $37.25 \pm 1.82)$. There was statistically significant progressive increase in activated partial thromboplastin time $(33.56 \pm 1.56,34.44 \pm 2.32,36.60 \pm 180 \mathrm{~s})$ and $(\mathrm{P}=0.001)$ fibrinogen $(362.22 \pm$ $21.72,369.82 \pm 22.65,378.54 \pm 17.69 \mathrm{mg} / \mathrm{dl})$. Also higher significant value in female compared with male (380.21 \pm 16.62 v $360.17 \pm 21.35$. The increase found in acute proteins, malondialdehyde, platelet count, fibrinogen and decrease in antioxidants, prothrombin time and APTT showed that type 2 diabetics is a state of chronic low grade inflammation, increased oxidative stress and hypercoagulable state which may result in increase morbidity and premature mortality of type 2 diabetes.

Keywords: Haemostatic parameters, type 2 diabetics, Owerri.

\begin{abstract}
Copyright @ 2019: This is an open-access article distributed under the terms of the Creative Commons Attribution license which permits unrestricted use, distribution, and reproduction in any medium for non-commercial use (NonCommercial, or CC-BY-NC) provided the original author and source are credited.
\end{abstract}

\section{INTRODUCTION}

Diabetes Mellitus is a chronic metabolic disease which is associated with a high incidence rate of morbidity and mortality globally. Type 2 diabetes mellitus is the most prevalent one and makes up $90 \%$ of cases of diagnosed diabetes [1]. Type 2 diabetes mellitus formerly known as non-insulin dependent diabetes mellitus or adult-onset diabetes is a metabolic disorder that is characterized by hyperglycaemia due to insulin resistance and relative reduced insulin secretion by beta pancreatic cells [2]. International Diabetic Federation [3] reported that 425 million (8.8\%) audits between the ages of twenty to seventy - nine years had diabetes and predicted to rise up to $625(9.9 \%)$ by the year 2045. According to Adeloye et al., [4], the pooled prevalence of type 2 diabetes in Nigeria in 2017 was $5.7 \%$. Also, the prevalence of $5.7 \%$ was reported by
Uloko et al., [5] as pooled geopolitical prevalence in 2018. In Imo State, the prevalence of type 2 diabetes was $8.7 \%$ was which reported among geriatric individuals [6].

Haemostasis is the process that maintains the integrity of circulating system after vascular damage [7]. Under normal circumstance, vessel wall injury rapidly initiates series of co-ordinate events designed to seal the breach generated by the injury. This leads to platelets recruitment and activation, blood coagulation; extrinsic and intrinsic way as well as generation of thrombin and fibrin [8]. Circulatory disturbances in diabetes are characterized b $\mathrm{y}$ alteration in platelet activity, coagulopathy, fibinolyti c aberration, haemorreologic factors and changes in endothelial metabolism [9]. Diabetes leads to hypercoaguble state which encompasses abnormalities 
such as thrombocytosis or antithrombin iii deficiencies and vascular endothelial cells are exposed to high glucose levels leading to elevation of tissue - type plasminogen activator in the plasma accompanied by impaired fibrinolysis [10].

The study aimed to evaluate the levels of acute phase inflammatory proteins, oxidative stress markers nd haemostatic parameters in Type 2 Diabetics.

\section{MATERIAL AND METHODS Study Area}

The cross sectional study was conducted at Federal Medical Centre, Owerri and Imo State Specialist Hospital, Owerri.

\section{Study Population}

The sample size for the study was calculated using the formula below, according to Aronye [11]. The prevalence rate of type 2 diabetes mellitus in Imo State is $8.7 \%$ [6].

$$
\mathrm{n}=\mathrm{z}^{2} \mathrm{p}(\mathrm{q}) / \mathrm{d}^{2}
$$

Where

$$
\begin{aligned}
& \mathrm{q}=1-\mathrm{P} \\
& \mathrm{n}=\text { Sample size } \\
& \mathrm{p}=\text { prevalence of type } 2 \text { of diabetes mellitus in } \\
& \text { Imo State- } 8.7 \% \\
& \mathrm{z}=\text { confidence interval } 95 \%-1.96 \\
& \mathrm{~d}=\text { Degree of accuracy- } 0.05 \\
& \mathrm{n}=1.96^{2} \times 0.087(1-0.087) / 0.05^{2}=3.8416 \mathrm{x} \\
& 0.07943 / 0.0025 \\
& =122.057=122 \\
& \text { Therefore, the minimum sample size will be } \\
& 122 .
\end{aligned}
$$

\section{Subjects}

Three hundred subjects of both sex between the ages of fifty to sixty-nine years were recruited for the study. One hundred and fifty type 2 diabetics attending clinic of Federal Medical Centre, Owerri and Imo State Specialist Hospital, Owerri for at least six months were eligible for the study. Also, one hundred and fifty apparently healthy individuals were recruited who came for check up for medical fitness and served as the control subjects.

They were further grouped according to their ages 40-49, 50-59 and 60-69 years, and also according to sex; male $(n=75)$ and female $(n=75)$

\section{Parameters Studied}

The parameters evaluated in this study include platelet count, prothrombin time, activated partial thromboplastin time and fibrinogen.

\section{Study Design}

This is a cross-sectional study that involved type 2 diabetics and control subjects.

\section{Site of the Study}

The analysis was carried out at the Haematolgy laboratory of the Department of Medical laboratory Science of Imo State University, Owerri and Federal Medical Center, Owerri through a letter obtained from the Head of Department through my Supervisor.

\section{Laboratory Procedure}

All reagents were commercially purchased and the manufacturer's standard operating procedures were strictly adhered to.

\section{Determination of Glucose}

This was carried out by enzymatic oxidase peroxidase method according to Tietz et al., [12] as modified by Randox Laboratories, United Kingdom. Catalog number; GL 1021, GL 304, GL366.

\section{Procedure}

Three dry cleaned plain test tubes were setup in a jack, labeled test, standard and blank. Then, $20 \mu \mathrm{l}$ of sample and standard wore pipetted into the tubes labeled these and standard respectively. In all the tubes, $2000 \mu \mathrm{l}$ of reagents I was added.The tubes were gently mixed, incubated at $37^{\circ} \mathrm{C}$ for 10 minutes. The absorbance of sample and standard were read spectrophotometrically at $500 \mathrm{~nm}$.

\section{Determination of Platelet Count}

This was carried out by direct current detecting method, according to Lewis et al., [13] using Sysmex Automated Haematology Analyzer KX-2IN Model.

\section{Procedure}

The sequenstrene blood sample was placed in the spiral mixer and allowed to mix well. The whole blood was activated in the LCD screen; the sample number (code) was imput by pressing enter. The sample was mixed well. The cap was removed and the sample inserted into the probe and the stand switch was pressed. The LCD screen displayed the analysis. The sample was removed and re-capped. The unit executed the analysis automatically and the result was displayed on the screen.

\section{Determination of Prothrombin Time}

The test was carried out by one stage prothrombin time according to Lewis et al., [13] as modified by Agappe Diagnostic Switzerland. Catalogue Number; 5261003, 52601004

\section{Procedure}

A clear dry test tube was set up in a rack. The reagent vial was swirled gently before use. The 
prothrombin regent was dispensed from the vial and it was pre-warmed of 370c for 10 minutes. $100 \mu \mathrm{l}$ of plasma was added to pre - warmed curvette and was incubated at $370 \mathrm{C}$ for 3 minutes. $200 \mu \mathrm{l}$ pre - warmed prothrombin reagent was added to be test curvette containing the pre-warmed sample. The time was started and the clotting time was recorded.

\section{Determination of Activitated Partial Thromboplasmin} Time

This was carried out by manual coagulation method according to Lewis et al., [13].

\section{Procedure}

The reagent vials were gently mixed to a homogenized suspension and swirled before use. Enough volume of reagent 1 Calcium chloride reagent 2 (APTT reagent) were pre-warmed at $37^{\circ} \mathrm{C}$ for ten minutes prior to use. A test curvette was set up at $37^{\circ} \mathrm{C}$ in a water bath, $100 \mu \mathrm{l}$ of plasma was pipette into it, followed by an addition $100 \mu$ of pre-warmed APTT reagent 2 well mixed and incubated for three minutes forcibly, $100 \mu$ of pre warmed reagent 1 (calcium chloride) was added into it... a timer was started simultaneously and the clothing time was read recorded in formation of clot in seconds.

\section{Determination of Fibrinogen}

This was carried out by semi automated coagulation method according to Clauss, 1957. As modified by Giessie Diagonstic, Italy. Catalogue number: 1004, 1005, 1006, 1007.

\section{Procedure}

A semi-automated Rayto 220c colgulotmeter was used. In a clean dry tube, $25 \mu 1$ of plasma was pipette into it and $225 \mu \mathrm{l}$ of imidazole buffer was added to make 1: 10 dilution. A test curvette was added into the holder and there was a display prompted to add sample displayed on the screen. Then $100 \mu$ l of diluted sample was pipette into the test curvette and it was incubated for five minutes and a display showed sample warming. There was another display in the screen prompted to add reagent, $50 \mu \mathrm{l}$ of thrombin was added with a display showing on the screen testing. The result was displayed on the screen and was recorded.

\section{STATISTICAL ANALYSIS}

Data was analyzed using software, statistical package for social science (SPSS), version 20.0. The results were expressed as mean and standard derivation (mean $\pm \mathrm{SD}$ ). Comparison of differences in the mean values between the groups were assessed using one way analysis of variance (Anova) and Independent student T - test. Variable between the age groups was assessed using Post Hoc test.

\section{RESULTS}

Table-1: Comparison of the Mean Values of Haemostatic Parameters in Type 2 Diabetes Mellitus and Control Subjects of the Study Population

\begin{tabular}{|l|l|l|l|l|}
\hline Parameters & $\begin{array}{l}\text { Type 2 diabetes } \\
\text { mellitus subjects } \\
(\mathbf{n = 1 5 0 )} \\
\text { mean } \pm \text { SD }\end{array}$ & $\begin{array}{l}\text { Control subjects } \\
(\mathbf{n = 1 5 0 )} \\
\text { mean } \pm \text { SD }\end{array}$ & T-test & P-value \\
\hline Platelet count $\left(10^{9} / \mathrm{L}\right)$ & $226.68 \pm 19.40^{*}$ & $205.86 \pm 13.33$ & 10.833 & 0.0001 \\
\hline $\begin{array}{l}\text { Prothrombin time }(\mathrm{S}) \\
\text { Activated partial thromboplastin }\end{array}$ & $13.47 \pm 1.25^{*}$ & $14.06 \pm 0.79$ & 7.920 & 0.031 \\
\hline time $(\mathrm{S})$ & $34.39 \pm 2.17^{*}$ & $37.25 \pm 2.10$ & 11.402 & 0.001 \\
\hline Fibrinogen $(\mathrm{mg} / \mathrm{dl})$ & $370.19 \pm 21.55^{*}$ & $263.58 \pm 32.31$ & 33.616 & 0.0001 \\
\hline
\end{tabular}

\section{KEY}

n: Number of subjects in each group

*: statistically significant when compared with type 2 diabetic group $(\mathrm{P}<0.05)$.

Table-1 shows the mean values of haemostatic parameter; platelet count and prothrombin time, activated partial thromboplastin time and fibrinogen in type 2 diabetics and control subjects. Result from this study, showed that the mean value of platelet count $(226.68 \pm 19.40)$ was higher in type 2 diabetics and was statistically significant $(\mathrm{P}=0.0001)$ when compared with the mean value $(205.86 \pm 13.33)$ of the control subjects.
The mean value of prothrombin time $(13.47 \pm$ 1.25) was lower in type 2 diabetics which was statistically significant $(\mathrm{P}=0.031)$ when compared with the control subjects $(14.06 \pm 0.96)$.

Result showed that the mean value of activated partial thromboplasmin time $(34.39 \pm 2.17)$ was lower in type 2 diabetics which was statistically significant $(\mathrm{P}=0.001)$ when compared with the mean value $(37.25 \pm 1.82)$ of the control subjects.

Inversely, the mean value of fibrinogen (370.19 \pm 24.55$)$ was higher in type 2 diabetics which was statistically significant $(\mathrm{P}=0.001)$ when compared with the mean value $(263.58 \pm 32.31)$ of the control subjects. 
Edward Ukamaka C et al; Saudi J Med Pharm Sci, Oct 2019; 5(10): 838-845

Table-2: The Mean Values of Haemostatic Parameters in Type 2 Diabetes Mellitus Subjects in Relation to Age of the Study Population

\begin{tabular}{|l|l|l|l|l|l|l|l|}
\hline Parameters & $\begin{array}{l}\text { 40-49 Years } \\
(\mathbf{n = 5 0 )} \\
\text { mean } \pm \text { SD }\end{array}$ & $\begin{array}{l}\text { 50-59 Years }(\mathbf{n = 5 0}) \\
\text { Mean } \pm \text { SD }\end{array}$ & $\begin{array}{l}\text { 60-69 } \\
(\mathbf{n = 5 0}) \\
\text { mean } \pm \text { SD }\end{array}$ & F-value & P-value & $\begin{array}{l}\text { P-value } \\
\text { a vs b }\end{array}$ & $\begin{array}{l}\text { P-value } \\
\text { b vs c }\end{array}$ \\
\hline Platelet count $\left(\times 10^{9}\right.$ Cells/L) & $231.44 \pm 18.44$ & $226.18 \pm 21.58$ & $222.42 \pm 17.23$ & 2.792 & 0.065 & 0.358 & 0.590 \\
\hline Prothrombin time (Seconds) & $13.60 \pm 1.31$ & $13.52 \pm 1.20$ & $13.28 \pm 1.23$ & 0.892 & 0.412 & 0.945 & 0.602 \\
\hline APTT (Seconds) & $33.56 \pm 1.56$ & $34.44 \pm 2.32$ & $36.60 \pm 1.80^{* *}$ & 10.320 & 0.0001 & 0.245 & 0.015 \\
\hline Fibrinigen (mg/dL) & $362.22 \pm 21.72$ & $369.82 \pm 22.65$ & $378.54 \pm 17.09^{*}$ & 7.836 & 0.001 & 0.160 & 0.091 \\
\hline
\end{tabular}

\section{KEY}
$\mathbf{N}$ : Number of subjects in each group
P - value: P- value across all type 2 diabetics age groups
$\mathbf{P}$ valuea vs b: $\mathrm{P}$-value of comparison between the age group of 40-49 and 50-59 years in type 2 diabetics
$P$ valueb vs c: $P$-value of comparison between the age group of 50-59 and 60-69 years
*: statistically significant when compared between the ages of 40-49 years $(\mathrm{P}<0.05)$.
**: statistically significant when compared between the ages of 50-59 years $(\mathrm{P}<0.05)$.

Table-2 shows the mean values of platelet count, and prothrombin time, activated partial thromboplastin time and fibrinogen in type 2 diabetics in relation to age.

There was progressive decrease in the mean value of platelet count acoss all age groups (231.44 \pm $18.44 ; 226.18 \pm 21.58 ; 222.42 \pm 17.23)$ which was not statistically significant $(\mathrm{P}=0.065)$. When the value between the ages $50-59$ years $(226.18 \pm 21.58)$ was compared with the ages between $40-49$ years (231.44 \pm 18.44), there was decrease which was not statistically significant $(\mathrm{p}=0.358)$ and also there was decrease which was statistically significant $(\mathrm{p}=0.590)$ when the value between 60 - 69 years $(222.42 \pm 17.23)$ was compared with the ages between 50- 59 years $(226.18 \pm$ 18.44).

There was no significant difference $(\mathrm{p}=0.892)$ in the mean value of prothrombin time among all the age groups $(13.60 \pm 1.31 ; 13.52 \pm 1.20 ; 13.28 \pm 1.23)$. There was no significant difference value between 40 49 years $(13.60 \pm 1.31)$ and $50-59$ years $(13.52 \pm 1.20)$ was not statistically significant $(\mathrm{p}=0.412)$. Also, the mean value of ages between $60-69$ years ( $13.28 \pm$ 1.23 ) with $50-59$ years $(13.52 \pm 1.20)$ was not statistically significant $(\mathrm{p}=0.602)$.

Result showed that there was progressive increase in the mean value of activated partial thromboplastin time across all ages $(33.56 \pm 1.56 ; 34.44 \pm 2.32 ; 36.56 \pm 1.80)$ which was statistically significant $(\mathrm{p}=0.001)$. The mean value between the ages of 50-59 years $(34.44 \pm 2.32)$ was increased but was not statistically significant $(\mathrm{p}=0.245)$ when compared with the mean value of ages between $40-49$ years $(33.56 \pm 1.56)$. The mean value between the ages of 60-69 years (34.44 \pm 2.32$)$ was increased, but was not statistically significant $(\mathrm{p}=0.245)$ when compared with the mean value of ages between 40-49 years $(33.56 \pm 1.56)$. Also the mean value of ages between 60-69 years (36.56 \pm 1.80$)$ was increased which was increased which was statistically significant $(\mathrm{p}=0.015)$ when compared with the mean value of ages between 50-59 years (34.44 \pm 2.32$)$.

There was a progressive increase in the mean value of fibrinogen across the ages $(362.22 \pm 21.72 ; 369.82 \pm 22.65 ; 378.54 \pm 17.09)$ which was statistically significant $(\mathrm{p}=0.001)$. the mean value between the ages of 50-59 years (369.82 \pm 22.65$)$ was increased which was no statistically significant $(\mathrm{p}=0.160+$ when compared with the mean value of ages between $40-49$ years $(362.22 \pm 21.72)$. the mean value of ages between 60-69 years $(378.54 \pm 17.09)$ was increased which was not statistically significant $(\mathrm{p}=0.091+$ when compared with the mean value of ages between $50-59$ years $(369.82 \pm 22.65)$.

\section{DISCUSSION}

In the study, higher level of platelet count was observed in type 2 diabetes when compared with the control subjects. Platelet hyperactivity occurs in type 2 diabetes when there was abnormal endothelial vascular dysfunction due to subclinical inflammation or cell wall injury which enhances vasoconstriction, increases release of cytokines and expression adhesion molecules such as intracellular cell adhesion molecules (ICAM) and vascular cell adhesion molecules (VCAM) which mediates platelets activation and adhesion to endothelium. This is in agreement with Soares et al., [14] that reported that hyper platelet activation result in 2 to 3 times higher coronary artery disease risk in diabetics. This is in accordance with studies conducted by Akinsegun et al., [15] that revealed higher mean platelet volume for diabetics. This agrees with the work of Alhadas et al., [16] that reported positive correlation of platelet count with the fasting blood glucose. Kaur et al., [7] observed high level of platelet as a result of endothelial and platelet hypersentivity which may involve in endothelial dyfunction and vascular 
disorders. Ferrein et al., [17] observed that high level of platelet count result from increase platelet reactivity which was induced by non-glycation of membrane protein that decreased membrane fluidity and platelet adhesion. This is also in agreement with Alhadas et al., [16], Pulani et al., [18] who observed higher platelet count and suggested that long term complication of diabetes with marked platelet morphorlogy could be associated with risk of developing vascular complication in diabetes contrary to present findings Buch et al., [19], reported that platelet count was significantly decreased in diabetics due to increased platelet activity. In contrast in a cross-sectional studies conducted by Chen et al., [20], there was no significant difference between platelet count and among diabetics when compared with non-diabetics. The study observed increase in various ages in type 2 diabetes which is not significant. This may be due to age related changes in platelet function in translocation platelets and unstable platelet interaction with von willie brand factor which result in increase adhesion to surface. This is in agreement by observational study conducted by Jones (2016). Also, Cowman reported that platelet function decreases in age due to decrease number of platelet tracking and interaction in von Williebrand factors. There was a slight increase in female type 2 diabetics which was not significant when compare with male diabetics. This may be due to reduction in oestrogen and deletion of oestrogen receptor in aged female which is expresses by platelet. This observation is supported by studies conducted Cowman et al., [21]; Zhao et al., [22].

The present study observed variation in blood coagulation. Lower level of prothrombin time was observed in type 2 diabetics when compared to control subjects. Prothrombin time is a screening test used to detect disorder involving contact with tissue factor which involve activation factor, ii, v, vii, ix, of extrinsic and common pathway. The shortened prothrombin time result from increased activation of hyperglycaemia induced glycation of coagulable protein ; prothrombin activation of coagulation factor which result in clot formation thrombosis increased premaline atherosclerotic plague formation rupture occlusive thrombus and hypercoagulable state include endothelial dysfunction, coagulative activation, platelet hypersensitivity as a result of hyperglylaemia insulin resistance inflammation of oxidative stress. The coagulation detect contributes lot micro vascular and macro vascular complication such as diabetic nephropathy, retinopathy, neuropathy cardiovascular, cerebrovascular peripheral vascular disease. The finding of this study is consistent with previous studies. Karim et al., [23] reported lower prothrombin time and concluded that type 2 diabetes were prone to develop coagulation defects. This is in concordance with the work of Ephram et al., [24] that found the association shortened PT. with or without diabetes complication as a coagulation risk factor in contrary to this study. Abdeen and Hamza et al., [25] observed prolongation of PT due to deficiency of coagulation factors in relation to diabetic duration. Thukral et al., [26] observed higher level of PTin type diabetics which indicated abnormal coagulation mechanism involving tendency of bleeding due to thromboembolic haemorragic disorder. A cross sectional study conducted by Obeagu et al., [27] showed no significant difference in the level of prothrombin time between diabetics and control subjects. Abdulla et al., [28] reported no significance in type 2 diabetics and control subjects. This study showed no significant difference in all age groups in type 2 diabetics. The findings are similar to the work of Ephraim et al., [24]; Thukral et al., [26] that reported no difference in age in PT level among diabetics. The findings of the study observed elevated level in female T2D which was not statistically significant. This may be due to increase in visceral obesity and hormonal changes such decrease in estrogen which may factor development of thrombosis. This agrees with the work of Ephraim et al., [24] that found insignificant increase in female diabetics. In contrary, there was no significant difference in PT level between male and female type 2 diabetics which was reported by Elendo et al., [29]; Abdulla et al., [28].

The current study observed low level of activated partial thromboplastin time (APTT).This is a coagulation maker used in assessing abnormalities in intrinsic and common pathway, contact with prekallikren high molecular, Kinnogen ,fibrinogen , coagulation inhibitors and natural anticoagulant. The low level of APTT in diabetics is a risk of hypercoagulable state which enhances thromboemobolic or occlusive thrombus within coronary or cerebral artery contributing to development of atherosclerotic lesion. This occurs due to hyperglycaemia glycation of intracellular and extracellular proteins which affect intrinsic clotting factors and triggers accumulation of these activated coagulation factor, delay action of coagulation inhibitors and fibinolytic system. The formation of uncontrolled thrombin is indicated by shortened APTT. The findings of this study are consistent with previous studies. Zhao et al., [30] reported low level of APTT in type 2 diabetes which reflects pro coagulation imbalance with increase level of coagulation of factor. Mwambungu et al., [31] reported low significant APTT in type 2 diabetes because T2DM patients are more prone to hyper coagulable state with increased thrombotic risk of cardiovascular events. This is in agreement with the work of Ankalayya et al., [32] who reported shortened APTT in type 2 diabetes with thrombotic risks. Ambelu et al., [33] reported low APTT level of $85 \%$ in untreated and $2.5 \%$ in treated type 2 diabetes. This agrees with the findings of Pan et al., [34] that reported shortened APTT in $\mathrm{T}_{2} \mathrm{D}$ was associated with diabetic complication such as 
nephropathy. This is consistent with the study of Agarwal et al., [32] that reported that low APTT occurred with or without diabetic complications. In contrary to this study, Alao et al., [35] reported significant prolonged due to thrombo haemorrhage shift in haemostasis balance. This is supported by the work of Obeagu et al., [27]; Abdeen and Hamza [25] found significant prolonged APTT level in type 2 diabetics as a result of inhibitors of intrinsic system and abnormal coagulation. Thurkral et al., [26] reported elevated plasma level of APTT which occurs due to defect in intrinsic coagulation, no significance difference was observed in the level of APTT between $\mathrm{T}_{2} \mathrm{D}$ and control subjects which was reported by Abdulla et al., [28]. The finding on the study observed significant decrease in APTT level in diabetes as the ages progress, this indicates that coagulation defect increase the thrombotic risk as the ages increase. The findings is not in accordance with the study of Elendo et al., [29]; Ephriam et al., [24] reported no significant difference between various age groups in type 2 diabetics. This study observed no significant difference between male and female type 2 diabetics. This is consistent with the work of Abdulla et al., [28] that reported no significant difference in type 2 diabetics in relation to sex.The findings to this study is inconsistent with work done by Elendo et al., [29] that reported significant increase in female when compared to male type 2 diabetics.

Higher level of fibrinogen was observed in type 2 diabetes when compared with the control subjects. This is due to non enzymatic glycation of fibrinogen that promotes adhension of endothelial receptors to platelet membrane, increases aggregation due to increase blood viscosity, reduction in tissue fibrinolysis from plasminogen to fibrinogen. Higher level of fibrinogen plays a role in formation of occlusive thrombosis over a rupture atherosclerotic plug in development of atherosclerosis in type diabetes. This implies that fibrinogen stimulates smooth cells proliferation and migration, increases coronary arterial diseases. The findings of this study agrees with the study of Bembale et al., [36] that reported higher level of fibrinogen due to increased thrombotic tendency in diabetics. Grupta et al., [37] also reported significant higher level of fibrinogen in diabetic with poor glycaemic control and its role in plague formation in form of occlusive thrombus over ruptured atherogenesity. This is similar to the findings of Yang et al., [38] that reported higher level of fibrinogen which is a marker of thromboembolism and inflammation that promotes ischemic stroke risk in diabetics. This is also consistent with the study by Elsayeed et al., (2018) reported higher fibrinogen level in type 2 diabetes due to changes in haemostatic mechanism that contributes to development of diabetic vascular diseases. There was progressive increase in fibrinogen level as the ages progress due to hepatic stimulation of fibrinogen which as associated with inflammation, indicated a link between inflammation and hypercoagulation in advanced ages. This is in agreement with the work of Gupta et al., [37]; Yang et al., [38] that reported that plasma level of fibrinogen increases with ages. There was higher level of fibrinogen in female when compared with male type 2 diabetics. This is because fat content and hormonal difference in woman. This is not in agreement with the study conducted by Bembale et al., [36] when reported insignificant higher level in female type 2 diabetics.

\section{CONCLUSION}

The findings of this study have shown that type 2 diabetics mellitus is associated with alteration in haemostatic system which is signified by platelet hyperactivity and hypercoagulable state. These undesirable state which play roles in the pathogenesis of type 2 diabetes may result in unexpected complications increased morbidity and premature death in type 2 diabetics.

\section{REFERENCES}

1. World Health Organization. (2016). Global reports on Diabetes. In World Health Organization Library.Meo design and communication. France. 1-84.

2. Fareed, M., Salam N., Khoja, A., \& Abdulrahman, M. T. (2017). Life Style Related Risk Factor of Type 2 Diabetes Mellitus And Its Increased Prevalence in Saudi Arabia. International Journal of Medical Research And Health Science. 6(3): 125-132.

3. International Diabetes Federation. (2017). Diabetes Atlas. $8^{\text {th }}$ Edition. 1-45.

4. Adeloye, D., Ige, J., Aderemi, A., Adelaye, V., Amoo, E., Auta, A., \& Oni, G. (2017). Estimating the prevalence, Hospitalization and Mortality from Type 2, Diabetes Mellitus in Nigeria. Biomedical Journal Open.7 (5): 1-16.

5. Uloko, A., Musa, B., Ramalam M., Gezawa, I., Puepit F., Uloko, A. Borodo M., \& Sada, K. (2018). Prevalence and Risk Factors for Diabetes Mellius in Nigeria: A Systematic Review and Meta-Analysis. Diabetes. Therapy. 9(3):13071316.

6. Iloh, G., Chukwu, A., \& Amadi, A. (2013). Burden of Non - Communicable Disease among Geriatric Nigeria in a Rural-Constraited. Setting of Eastern Nigeria.Science Journal of Public Health, 1:141-146.

7. Kaur R., Kaur M., \& Singh J., (2018). Endothelial Dysfunction and Platelet Hyperactivity in Type 2 Diabetes Mellitus: Molecular Insights and Therapeutic Strategies. Cardiovascular Diabetology. 17:121.

8. Lemkes, B., Hermanides, J., Devries, J., Holleman, F., Meijers, J., \& Hockstra, J. (2010). Hyperglycaemia, A protrombotic factor? Journal of thrombosis and Haemostatis. 8:1663-1669. 
9. Holinstat, M. (2017). Normal Platelet Function. Cancer Metastasis Review. 36(2): 195-198.

10. Khalifa, J., \& Abdul-Raheem, E. (2013). Haemostatic Profile in Saudi Patients with Type II Diabetes Mellitus. International Journal of Health Sciences and Research. 3(8):31-34.

11. Aronye, M. (2004). Size Determination In: Research Methodology with Statistics for Health and Social Sciences. $1^{\text {st }}$ Edition, Nathadex Publishers. Illorin, 115-121.

12. Tietz, J. (2006). Boss Hog: The Dark Side of America's Top Pork Producer. Rolling Stone.

13. Lewis, M., Brain, B., \& Bytes, I. (2006). Investigation of Haemostasis in: Dacie and Lewis Practical Haematology. $10^{\text {th }}$ Edition. Church Hill Living Stone. United Kingdom. 379-440.

14. Soares, A., Sousa, M., Fernandes, A., \& Carvalho, M. (2016). Hemostasis Changes in Patients with Type 2 Diabetes Mellitus. Revista Brasileira De Haemotologia Hemoterapia. 32(6): 482-488.

15. Akinsegun, A., Olusola, D., Sara, J., Olajumoke, O., Adewumi .A, Majeed .O, Anthonia, O., Gbelle, U., Olaitan, O., Olanrewaju, A., \& Kingsley, A. (2014). Mean Platelet Volume and Platelet Counts in Type 2 Diabetes Treatment and Non-diabetes Mellitus Controls in Lagos. Pan African Journals. 20(4):18.

16. Alhadas, K., Santos, S., Treitas, M., Viana, S., Ribeiro, L., \& Costa, M. (2016). Are Platelets in Indices Useful in the Evaluation of Type 2 Diabetic Patients. Journal Brasileiro de Patrologia medicina laboratorial. 52(2):96-102.

17. Ferrein, A. (2010). Robot controllers for highly dynamic environments with real-time constraints. KI-Künstliche Intelligenz, 24(2), 175178.

18. Pulanić, D., Desnica, L., Perić, Z., Samardžić, A., Grce, M., Vrhovac, R., \& Pavletić, S. Ž. (2018). Zagreb-center of chronic Graft-versus-Host Diesease in November 2018.

19. Buch, A., Kaur, S., Nair, R., \& Jain, A. (2017). Platelet Volume Indices as Predictive Biomarkers for Diabetic Patients Journal of Laboratory Physicians. 9(2):84-88.

20. Chen, X., Fang, L., Lin, H, Shen, P., Zhang, F., Li, H., Li, X., Yu, .M, Xu, C., Zhang, J., Lu, F., Du, X., Du, X., Hu, R., \& Zhong, J. (2017). The Relationship between Type 2 Diabetes and Platelet Indicators. Iranian Journal of Public Health. 4(9):1211-1216.

21. Cowman, J., Dunne, E., Kenny, D. Ogelesby, I., Byrne, B. Ralph, A., Voison, B., Muller, S., \& Riao, A. (2015). Age-Related Changes in Platelet Function are more Profound in Women than Men. Scientific Reports. 5:12235.

22. Zhao, F., Yan .Z., Meng, Z., Li, X., Ming,L., Ren, X., Zhu, M., He, Q., Zhang, Q., Song,K., Jia, O., Zhang, C., Wang, Liu, X., Zhang, X., Pan, Z., Liu, X. H., \& Zhang, W. (2018). Relationship between
Mean Platelet Volume and Metabolic Syndrome in Chinese Patients. Scientific Report. 8:14574.

23. Karim, F., Akter, S., Jahan, S., Khanom, A., Haque, S., Yeasmin, T., Siddika, T., \& Sinha, S. (2015). Coagulation Impairment in Type 2 Diabetes mellitus Journal of Bangladesh Society and Physiology. 10(1): 26-29.

24. Ephraim, P., Awuka Y., Adu, P., Ampomah, L., Adoba, P., Abalzakey H., Panord, S., \& Ninnoni, J. (2017). High risk of Coagulopathy among Type 2 diabetes mellitus client at a municipal Hospital in Ghana.Ghana Medical Journal. 3: 101-107.

25. Abdeen, H., \& Hamza, K. (2013). Prothrombin Time PT and Activated Partial Thromboblastin Time (APTT) in Sudanese Diabetic Datients. Journal of Natural and Medical Science. 16 (1).

26. Thukral, S., Hussain, S., Bhar S., Kaur, N., \& Reddy, A. (2018). Prothrombin Time (PT) and Activated Partied Thromboplastin Time (APTT in Type 2 Diabetes Mellitus, A Case Control Study. International Journal of Contemporary Medical Research 5(8): H5-H8.

27. Obeagu I., Obarezi H., Aloh, S., \& Emelike, U. (2014). Changes in Some Coagulation Parameters Among Diabetes Patients in Michael Okpara University Of Agriculture, Umudike Abia State Nigeria. Journal of Pharmacy and Pharmaucetical Science, 3(4):52-61.

28. Abdulla, A., Elmissabah, T., Hamid, E., A-Itom, F., \& Abusham, M. (2017). Assessment and coagulation process in diabetes patients mellitus and Healthy individuals International Journal of Contemporary Medical Research. 3(11): 31703170.

29. Elendo, B., Nwoaga M., Okamgba, O., \& Izuh, S. (2017). Assessment of Some Haemostatic Parameter among Diabetes Mellitus Patients In Bayelsa State: A Case Study at The Federal Medical Center, Yenugoa. European Journal of Clinical and Biomedical Science, 3(5):91-96.

30. Zhao, J., Jin, H., Gao, J., Pu, C., Zhang, P., Huang, J., Cheng, L., \& Feng, G. (2018). Serum Extrantracellular Superoxide Dismutase is Associated with Diabetics Retinopathy Stage in Chinese Petients with Type 2 Diabetics Mellitus. Disease Markers, 8721379:1-9.

31. Mwambung, A., Kalie T., Korolova L., Kwenda J., \& Marimo C. (2013). APTT A Screening Test for Hypercoagulability in Type 2 diabetes mellitus Medical Journal of Zambia, 40(3):112-118.

32. Agarwal, C., Bansal, K., Pujani, M., Singh, K., Chauhan, V., Rana, D., \& Lukhmana, S. (2019). Association of coagulation profile with microvascular complications and glycemic control in type 2 diabetes mellitus-a study at a tertiary care center in Delhi. Hematology, transfusion and cell therapy, 41(1), 31-36.

33. Ambelu, G., Lovelock, B., \& Tucker, H. (2018). Empty bowls: conceptualising the role of tourism 
in contributing to sustainable rural food security. Journal of Sustainable Tourism, 26(10), 1749-1765.

34. Tacconelli, E., Carrara, E., Savoldi, A., Harbarth, S., Mendelson, M., Monnet, D. L., ... \& Ouellette, M. (2018). Discovery, research, and development of new antibiotics: the WHO priority list of antibiotic-resistant bacteria and tuberculosis. The Lancet Infectious Diseases, 18(3), 318-327.

35. Alao, O., Damulak, D., Joseph, D., \& Puepet, F. (2009): Haemostatic profile of Patients with Type 2 Diabetes Mellitus in Northern Nigeria. The Internet Journal of Endocrinology. 6(1):1-7.

36. Bembde, A. (2012). A Study of Plasma Fibrinogen Level In Type 2 Diabetes Mellitus And Its Relation to Glycaemic Control. International
Journal of Haematology and Transfusion. 28(2); 105-108.

37. Gupta, P., Bhambani P., \& Narang, S. (2016). Study of Plasma Fibrinogen Level and Its Relation to Glycaemic Control in Type 2 Diabetes Mellitus Patients Attending Diabetes Clinic at a Tertiary Care Teaching Hospital in Madha Pradaesh India. International Journal of Research in Medical Sciences. 4(9) 3748-3754.

38. Yang, S., Du Y., Zhang, Y., Lin, X., Li, S. Xu, R., Zhu, C., Guo, Y., Wu, N., Qing, P., Gao, Y., Cui, C, Dong, Q., Sun, J., \& Li, L. (2017) Serum Fibrinogen and Cardiovascular Events In Chinese Patients with Type 2 Diabetes And stable coronary Artery Disease. BMJ Open, 7(6):e015041. 